\title{
From observation to the quantification of snow processes with a time-lapse camera network
}

\author{
J. Garvelmann, S. Pohl, and M. Weiler \\ Chair of Hydrology, University of Freiburg, Freiburg, Germany \\ Correspondence to: J. Garvelmann (jakob.garvelmann@hydrology.uni-freiburg.de) \\ Received: 5 September 2012 - Published in Hydrol. Earth Syst. Sci. Discuss.: 20 September 2012 \\ Revised: 20 March 2013 - Accepted: 21 March 2013 - Published: 12 April 2013
}

\begin{abstract}
A network of 45 spatially distributed time-lapse cameras was used to carry out a continuous observation of snow processes and snow cover properties throughout three mid-latitude medium elevation mountain catchments in hourly intervals during the winter seasons of 2010/2011 and 2011/2012. A simple technical modification was conducted to enable the deployment of the standard digital cameras in any location. Image analysis software was applied to extract information about snow depth, surface albedo and canopy interception from the digital images. Furthermore, the distributed design of the camera network made it possible to identify the elevation of the snow rain interface for any precipitation event which is very helpful for the interpretation of winter flooding events resulting from snow melt. Exemplary data for all these analyses is presented to show the potential fields of application of this innovative approach. Study results prove that the application of digital time-lapse photography is an appropriate technique to observe the spatial distribution and temporal evolution of seasonal snow covers in a mountainous environment.
\end{abstract}

\section{Introduction}

Snow is an important component of the hydrological system in many mountainous environments. Vegetation and topography have a crucial influence on the spatial distribution and temporal evolution of snow covers and the relation of all factors influencing the distribution have not been well understood (e.g., Jost et al., 2007, 2009). A continuous monitoring of the snow cover at the catchment scale is valuable to improve the understanding of the processes driving the spatiotemporal variability of seasonal snow covers. Furthermore, it yields important information for water resource applications and the prediction of snow melt runoff events.

The interception of snow in the forest canopy is a major factor contributing to the difference in snow accumulation between open and forested areas (Hedstrom and Pomeroy, 1998; Storck et al., 2002). Different processes (mass unload, sublimation and melt water drip) are involved in the unloading of snow from the canopy (Pomeroy et al., 1998).

Incoming global radiation is often the most important component of the snowmelt energy balance. The albedo of the snow surface describes the fraction of absorbed shortwave radiation, therefore, strongly influencing the energy balance in snowmelt. Snow albedo values decrease after a fresh snowfall mostly due to metamorphic snow processes. During the metamorphose snow grain sizes are increasing, resulting in a decreasing albedo (Wiscombe and Warren, 1980). In addition, particles (aerosols, dust, needles and small branches) falling on the snow are also contributing to a decrease of snow surface albedo (Warren and Wiscombe, 1980; Hardy et al., 2000; Melloh et al., 2001). Different albedo decay functions have been used so far in modelling snowmelt (e.g., Gray and Landine, 1987; Link and Marks, 1999; Garen and Marks, 2005; Pomeroy et al., 2007; Mazurkiewicz et al., 2008). Albedo and its parameterisation is a crucial factor in modelling the net shortwave radiation. Etchevers et al. (2004) showed the significance of the albedo parameterisation for the simulation of the net shortwave radiation in a model comparison study. There are many approaches with diverse degrees of complexity to model snow surface albedo. Most of the approaches, however, include the use of a time dependent albedo decay function. Jost et al. (2009), for example, applied a snow melt model in a forested environment. They observed that the decline of the 
predicted albedo decay in the used model is generally too fast. As a consequence they introduced different albedo decay functions for forested and open sites that were derived by fitting to observed albedo values in order to calculate realistic snow ablation rates, showing the importance of having continuous in situ albedo observations. In situ measurements of surface albedo are usually conducted with an albedometer, consisting of two pyranometers one directed upward measuring the incoming shortwave radiation and another one directed downward for detecting the reflected short wave of the surface. Remote-sensing methods have also been used to determine surface albedo (Knap et al., 1999; Greuell et al., 2002; Klein and Stroeve, 2002). These techniques as well as the direct in situ measurements are expensive, limited to single point measurements (albedometer), or limited to a few snapshots (remote sensing). Therefore, there is a demand for alternative techniques for the continuous estimation of spatially variable surface albedo.

Manual snow surveys have been used in various studies to measure the evolution of the snow pack (e.g., Stottlemyer and Troendle, 2001; Lundberg and Koivusalo, 2003; Winkler et al., 2005; Jonas et al., 2009). However, these surveys only provide snapshots of the snow cover evolution over the winter. Continuous observations at the catchment scale are missing and, therefore, event-based analysis of snow cover properties and snow processes is often not possible.

Terrestrial time-lapse photography is a non-destructive method and, compared to satellite remote-sensing techniques, it is relatively economic and allows for a high spatial and temporal resolution. In snow research, time-lapse photography has been used to observe the distribution and patterns of snow covers (e.g., Hinkler et al., 2002; Farinotti et al., 2010). Floyd and Weiler (2008) have shown that timelapse photography is an appropriate technique for an event based analysis of accumulation and ablation of snow, interception of snow in the forest canopy and subsequent unloading. Furthermore, they used the images to monitor the state of precipitation. Parajka et al. (2012a) showed the potential of time-lapse photography for the observation of the spatio-temporal variability of snow depth and interception in the near range (100-300 m) and snow cover patterns in the far range (circa 1000-2000 m) of the camera view, respectively. An overview of studies using time-lapse photography in glaciology and snow research can be found in Parajka et al. (2012a).

In this study, we extend these approaches further by modifying standard digital cameras to run independently of any outside stationary power source. This allowed us to set up an experimental design consisting of a network of numerous standard standalone digital time-lapse cameras distributed throughout the study watersheds and covering a wide variety of topographical situations with varying land covers (open, deciduous forests, conifer forests, mixed forests). In addition, we automated and extended the information that can be gained from the time-laps images to derive time series of snow depth, snow interception, albedo and the state of precipitation. The intention of this paper is to demonstrate the potential of such a distributed network of numerous standard digital cameras as an observation tool at the catchment scale and to provide exemplary datasets for the mentioned applications.

\section{Methodology}

\subsection{Study area and observation network}

The study was conducted in the Black Forest, a typical midlatitude medium elevation mountain range in the southwest of Germany. The mountain range has elevations ranging from approximately $400-1493 \mathrm{~m}$ a.s.l. Average winter season air temperatures are ranging from $4.1^{\circ} \mathrm{C}$ in the lower parts to $-2.1^{\circ} \mathrm{C}$ in the highest elevations. Mean annual precipitation ranges from approximately $900 \mathrm{~mm}$ in the lower parts to about $1950 \mathrm{~mm}$ in the higher regions. More than half of precipitation is falling during the winter months.

On average only $3 \%$ of the study catchment areas are covered by human settlements while $27 \%$ are open areas used for grazing and haymaking. The remaining $70 \%$ of the area is covered by forest. The forests in the Black Forest are about $80 \%$ coniferous (spruce, fir, pine) and $20 \%$ deciduous (beech, birch, oak). The most common needle leaf species is the European spruce (Picea abies), while the most common deciduous tree species is beech (Fagus sylvatica). Leaf Area Indexes in the study catchments are ranging from 1.52 to 2.63 for conifer stands and from 0.88 to 1.66 for deciduous stands.

In order to accomplish a continuous observation of the quantity and the status of the snow cover, a network of 15 standalone digital time-lapse cameras was established over the winter season 2010/2011 in a mesoscale catchment. The network was extended to 45 cameras spread over three watersheds (Brugga: $47^{\circ} 54^{\prime} 40^{\prime \prime}$ N, $7^{\circ} 55^{\prime} 47^{\prime \prime} \mathrm{E}$; Kinzig: $48^{\circ} 21^{\prime} 32^{\prime \prime} \mathrm{N}, 8^{\circ} 25^{\prime} 30^{\prime \prime} \mathrm{E}$; Breg: $48^{\circ} 01^{\prime} 39^{\prime \prime} \mathrm{N}, 8^{\circ} 15^{\prime} 33^{\prime \prime} \mathrm{E}$ ) of different sizes and topographic characteristics for the 2011/2012 winter (Fig. 1). Within the study catchments, a stratified sampling design was used to cover a wide range of altitudes and exposures. To specifically investigate the influence of the vegetation cover on the accumulation and ablation processes of the snowpack beneath, generally pairs of cameras were installed in close proximity to each other with one being located underneath the forest canopy while the other was situated on an adjacent open field site.

In addition to the camera network, data on snow depth, air temperature and humidity from 18 observation stations (LOCUS) deployed in the Brugga catchment was used to validate the results from the camera network. A comprehensive description of the LOCUS sensor system can be found in Varhola et al. (2010). The 18 stations were divided into nine 


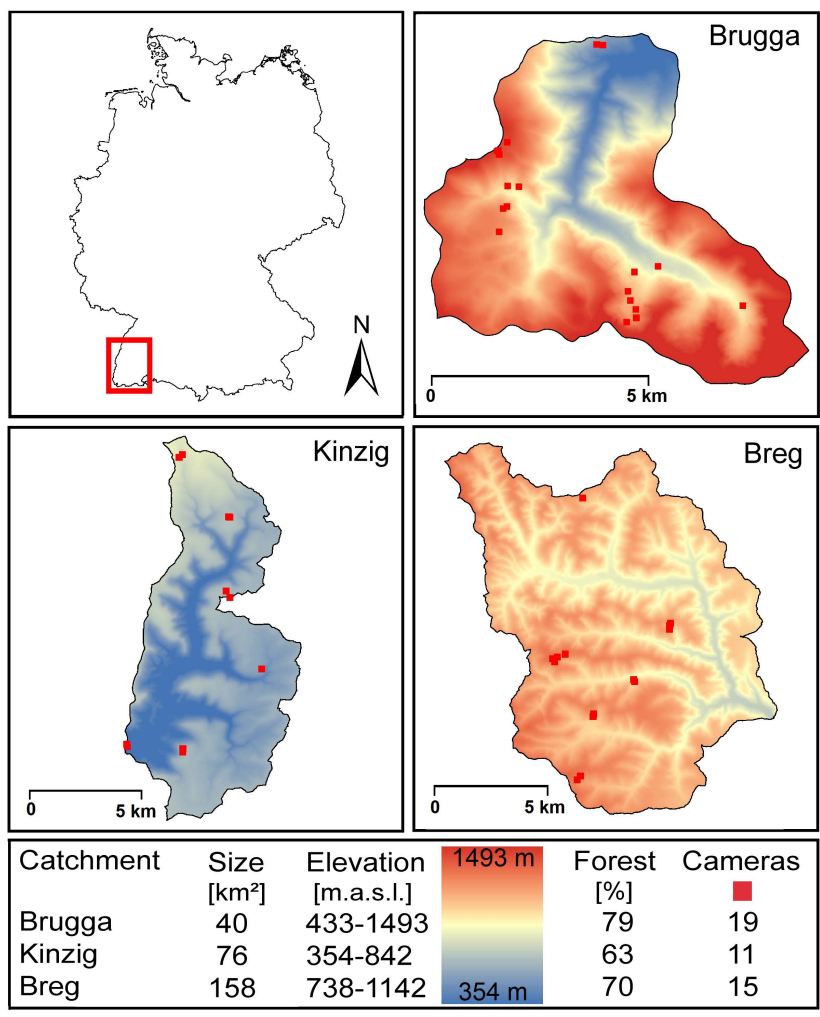

Fig. 1. The three study catchments in the Black Forest, southwest Germany showing the locations of the camera network.

pairs of LOCUS stations (with one station in the forest and another one on an adjacent open field site).

\subsection{Camera design}

We used a standard Pentax Optio W90 digital camera, which is a waterproof outdoor camera. The camera is equipped with a 12 megapixel 1/2.3" RGB-CCD-sensor chip and allows to electronically set-up a time-laps routine. Hourly pictures were stored on a camera internal $2 \mathrm{~GB}$ SD-card. The timelapse mode of the camera allows for a maximum of $1000 \mathrm{im}-$ ages. Therefore, the cameras had to be read-out and restarted after a maximum duration of 41 days. To ensure a continuous power-supply for the digital camera, we used a 3.7 Volt external rechargeable Lithium-Polymer battery - Kokam Superior Lithium Polymer Batteries, 3.7 V, $3200 \mathrm{mAh}\left(20^{\circ} \mathrm{C}\right)$. Rechargeable Lithium-Polymer batteries are known to provide reliable power supply even for low temperatures. Cables were soldered to the camera internal battery terminals, which we connected with gold plated plugs to the rechargeable Lithium-Polymer batteries (Fig. 2). With this modification we were able to install and run the digital cameras independently of any additional power source at any location in the field. This gave us complete freedom to choose adequate locations to suit our research questions. It also made the installation comparably easy and time efficient, which was essential for setting up the high density camera network used in this study. To protect the cameras from severe weather conditions and minimise drops on the camera lens, they were mounted within wooden birdhouses, which were then mounted to trees and other suitable objects in the field (Fig. 2). The birdhouses also helped us to reduce vandalism of the equipment in the watersheds.

\subsection{Image analysis}

For the image analysis, we used self-written codes in IDL (Integrated Data Language) embedded in the IDL software package version 8.0, to extract information about snow depth, albedo and the interception of snow in the forest canopy. A wooden measurement stake with alternating $10 \mathrm{~cm}$ black and red bars was installed in camera view at every location to accommodate the snow depth estimation. We used $1.30 \mathrm{~m}$ stakes at low elevation sites and $1.70 \mathrm{~m}$ stakes at higher altitudes, respectively. On top of the stakes a black and a white plastic board was attached to provide a control surface area for each picture. Having these boards in the pictures allows the direct determination of the references for black and white for differing illumination conditions in the image analysis. The reflectance of the white reference surface was determined at different illumination conditions and used for the albedo estimation, whereas the black and white boards were used for the calculation of canopy interception by computing a differentiation between white and black pixels at differing illumination conditions. Polygon masks, called regions of interest (ROI), were defined within each image to define the areas within the pictures for which snow surface albedo and canopy interception calculations were carried out (Fig. 3). Several ROIs for albedo or interception analysis can be defined within the pictures providing more representative average values for a location, but also allowing an analysis of the potential variability of those values at a location.

A batch analysis routine was used to load and analyse each image. RGB values for every pixel within the defined polygon masks and the control surfaces (black/white board) are used for the calculations. The calculated output was written to a text file, which could be used for further analysis. Images taken at night and during poor visibility conditions (fog, intense snowfall events) were discarded and could not be used for the image analysis resulting in data gaps.

The established camera network allowed a continuous observation of snow depths at different locations throughout the catchments. These snow depth time series and accompanying snow surveys, which determined snow densities, can be used to calculate snow water equivalents (SWE). A semiautomatic approach for the snow depth analysis was developed. First the number of pixels of a $10 \mathrm{~cm}$ bar of the stake was determined. Secondly the number of pixels of the portion of the stake not covered by snow at a particular location was detected. For this purpose the cursor procedure of IDL was used which allows the reading of the position ( $x y$ values) 

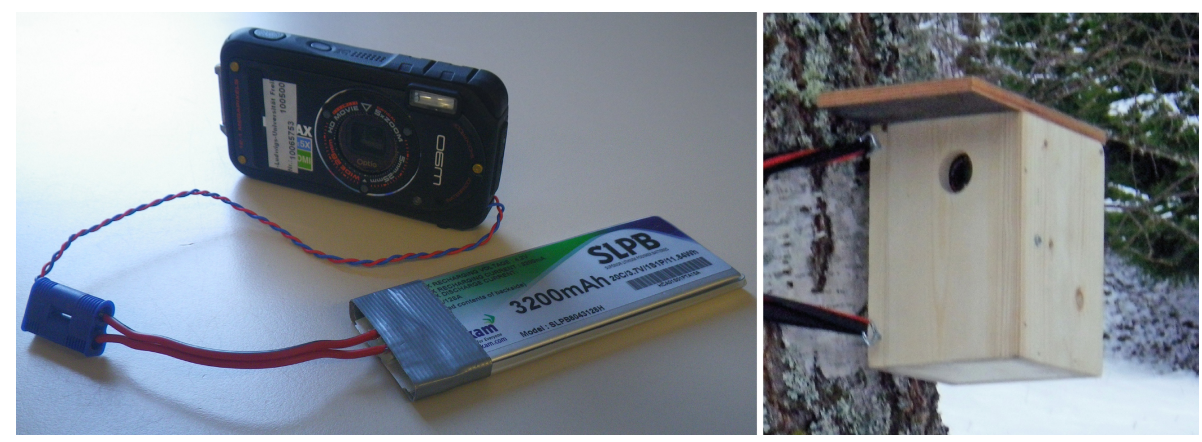

Fig. 2. Camera setup used in the presented study. Set-up of the additional battery (left panel) and installation in the field within a bird house as a protection against the weather (right panel).

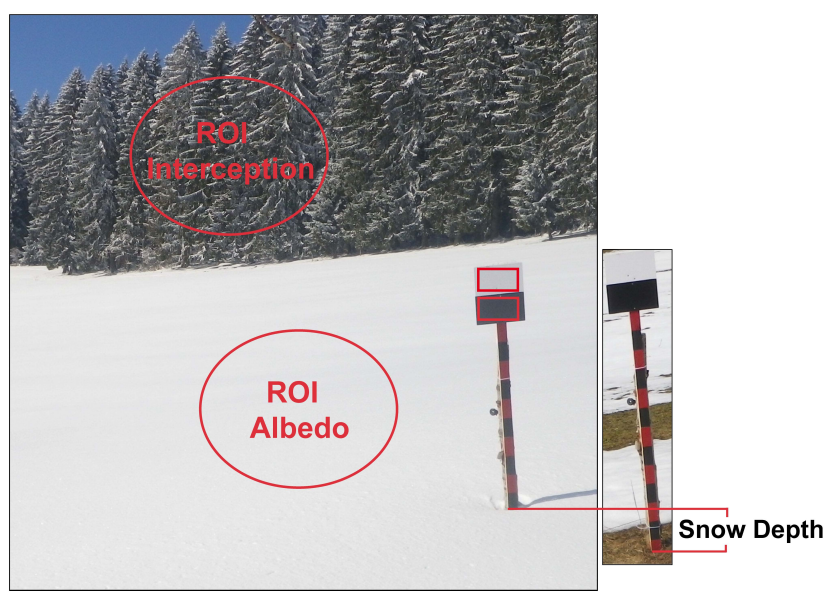

Fig. 3. Example of a picture at one location and the defined areas (ROI) for determining albedo and interception and the stake to determine snow depth semi-automatically.

of a cursor click within the digital image. For each image, a cursor click was carried out at the upper and the lower edge of a $10 \mathrm{~cm}$ bar and at the upper end of the stake and the snow level at the stake, respectively, providing the length of the stake not covered by snow. The snow depth was subsequently calculated by a subtraction of the stake length not covered with snow from the total length of the stake. After this calculation the routine opens the next image. Fully automated approaches based on counting the number of snow stake pixels not covered with snow by using the colour of the stake bars are presented by Floyd and Weiler (2008) and Parajka et al. (2012a). To check the accuracy of this semi-automated process, we also determined the snow depths "manually" by opening each picture and determining the snow depth by counting the visible red and black bars by eye. Figure 4 shows the comparison of the two methods for one location. The comparison shows that the overall evolution of the snow depth over the winter is reproduced well by the semi-automated method $\left(R^{2}=0.98\right.$, RMSE $\left.=7.1 \mathrm{~cm}\right)$. However, there seems to be a constant slight underestimation

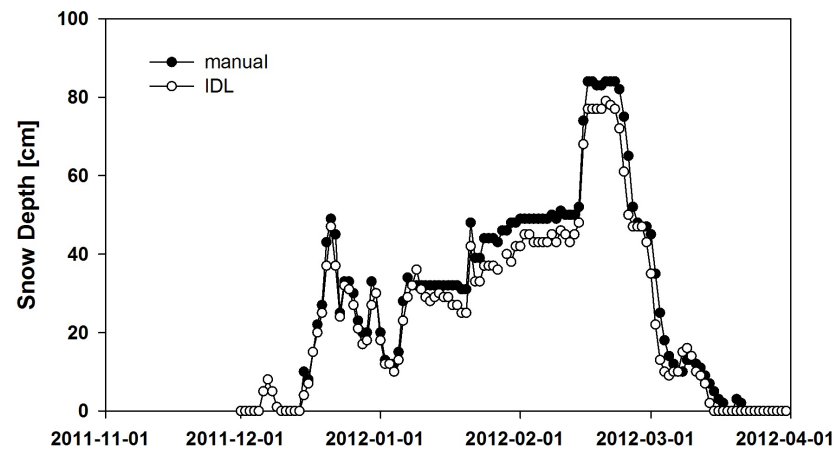

Fig. 4. Comparison between the manually derived snow depths and the results from a semi-automated IDL routine.

of snow depths at higher values. Furthermore, some locations showed minor alterations of the snow depth around the stakes due to preferential deposition and melting of the snow close to the stakes. For these reasons, we chose to "manually" determine the snow depths from the digital images for this study.

Since the CCD-sensor in the applied camera has a filter for eliminating the near infrared component of the electromagnetic spectrum, the camera can only be used to detect the visible range of the electromagnetic spectrum. Therefore, we can only estimate the snow surface albedo within the visible range. Nevertheless, Corripio (2004) has shown that terrestrial photography is a suitable and useful approach to estimate snow surface albedo. He used an algorithm for georeferencing the images in order to correct the reflectance values of the images with respect to the topographic position. In this study, we used an even simpler approach based on Gorski (2013) to estimate surface albedo values in the visible range of the electromagnetic spectrum directly from the digital images. After Gorski (2013) the calculated albedo value is the ratio of the mean RGB pixel values of a white reference surface (recommended is a white piece of paper) and the mean RGB pixel of the earth surface within the digital image. This ratio is multiplied with a factor which is dependent on the reflectance value of the reference surface. Gorski (2013) 

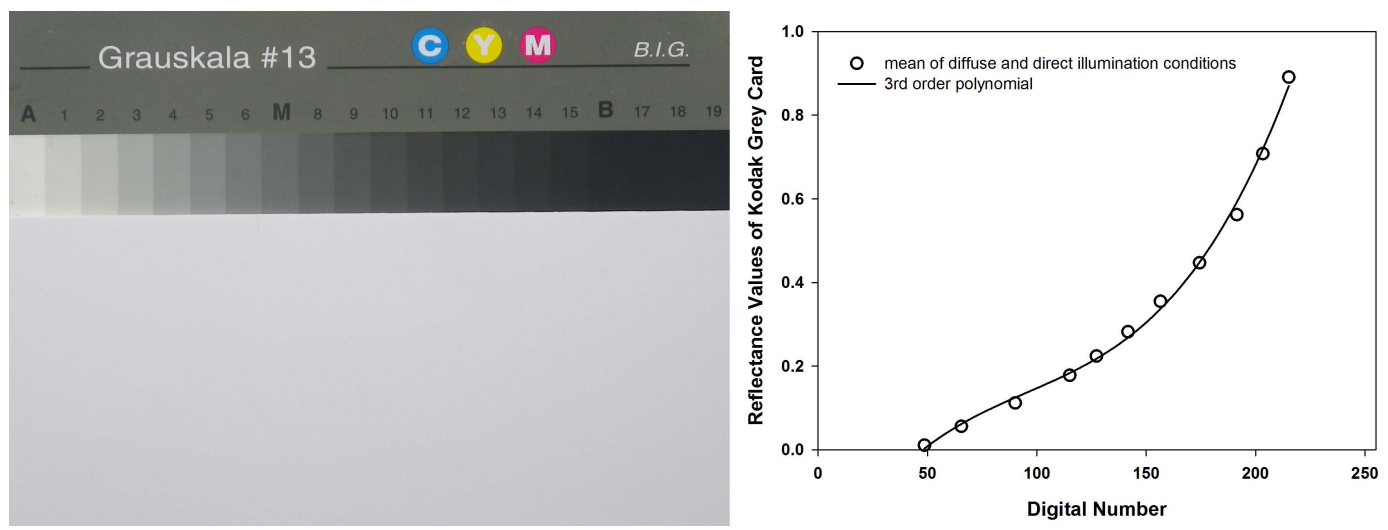

Fig. 5. Kodak gray card Q13 with the used reference board below (left panel). Relationship between the digital number derived from the gray card patches and the respective reflectance values (right panel).

suggest a multiplication factor of 0.6 when using a CCDsensor camera for an albedo calculation with a white piece of paper as a reference surface.

Albedo $=f \cdot \frac{\text { Reflectance }_{\text {Surface }}}{\text { Reflectance }_{\text {Reference }}}$

whereas, $f$ describes the multiplication factor,

Reflectance Surface $_{\text {is }}$ the calculated reflectance of the surface in the images and

Reflectance Reference $_{\text {is }}$ the calculated reflectance of the reference board in the images.

Similarly, our approach uses the reflectance value of the reference board and the surface in the digital images for the calculation of the albedo. A problem is that we do not know the reflectance values of the used white reference surface and the response of the used digital camera for varying illumination conditions. In order to estimate the reflectance values of the reference white board in the digital images we used a Kodak Q13 gray card, which is a standard calibration card with known reflectance values. We took images of the grey card and the white reference board (Fig. 5) under direct and diffuse illumination conditions. From these pictures we calculated the digital numbers (mean of the pixel RGB values) of the gray card patches and the white plastic board. Then we plotted the digital numbers against the reflectance values of the gray card patches and fitted a 3rd order polynomial function. With this function, we got reflectance relationships for the camera type used (Fig. 5) for direct and diffuse illumination conditions and we estimated an average function. Since there is an over-representation of dark gray card patches and since we were especially interested in acquiring accurate values for the lighter colours useful for the snow albedo determination we discarded the data from nine $(8,10,11,13,14,15, \mathrm{~B}, 17,18,19)$ of the 20 plots in order to get an equally weighted polynomial function over the whole gray card range. The 3rd order polynomial function was used for a calculation of the reflectance value of the reference board, which was 0.66 for direct, 0.715 for diffuse light and 0.687 estimated from the average function. This averaged value was used as the multiplication factor $f$ (see Eq. 1) for the albedo calculations, since this is the mean reflectance of the reference board during differing illumination conditions.

In the image analysis routine for the albedo calculation, for each picture the mean RGB value of the polygon mask located on the white reference surface within the image is used to calculate the reflectance of this surface using the average 3rd order polynomial function. The same routine is then carried out for three polygon masks located on the snow surface within the digital images. The location of these three masks was held constant from picture to picture at a particular location. In the image analysis code the ratio of these two reflectance values is calculated and multiplied with the multiplication factor of 0.687 according to Eq. (1) for every image used for analysis. The varying daily angle of incoming solar radiation affects the illumination conditions on the surface and the reference board. Furthermore, the angle of the snow surface is permanently changing due to accumulation, redistribution and melt processes and the angle of the camera to the reference board is constantly changing due to slight movements of the camera. To take all these changing conditions into account, we calculated daily means of snow albedo from the hourly images during daylight.

For the calculation of snow interception in the forest canopy, we first performed a black/white balance determination using the control surfaces mounted on top of the snow stakes in the images. We then defined ROI polygon masks that were entirely within the forest canopy making sure that no snow on the ground was included in the ROI as this would introduce a substantial error. Based on the black/white balance white (snow) pixels could then be distinguished from non-white (non-snow) pixels within the polygon masks and a fraction of snow (white pixels) could be calculated. A fraction of zero would, therefore, indicate no snow in the canopy and a fraction of one would indicate a completely snow 

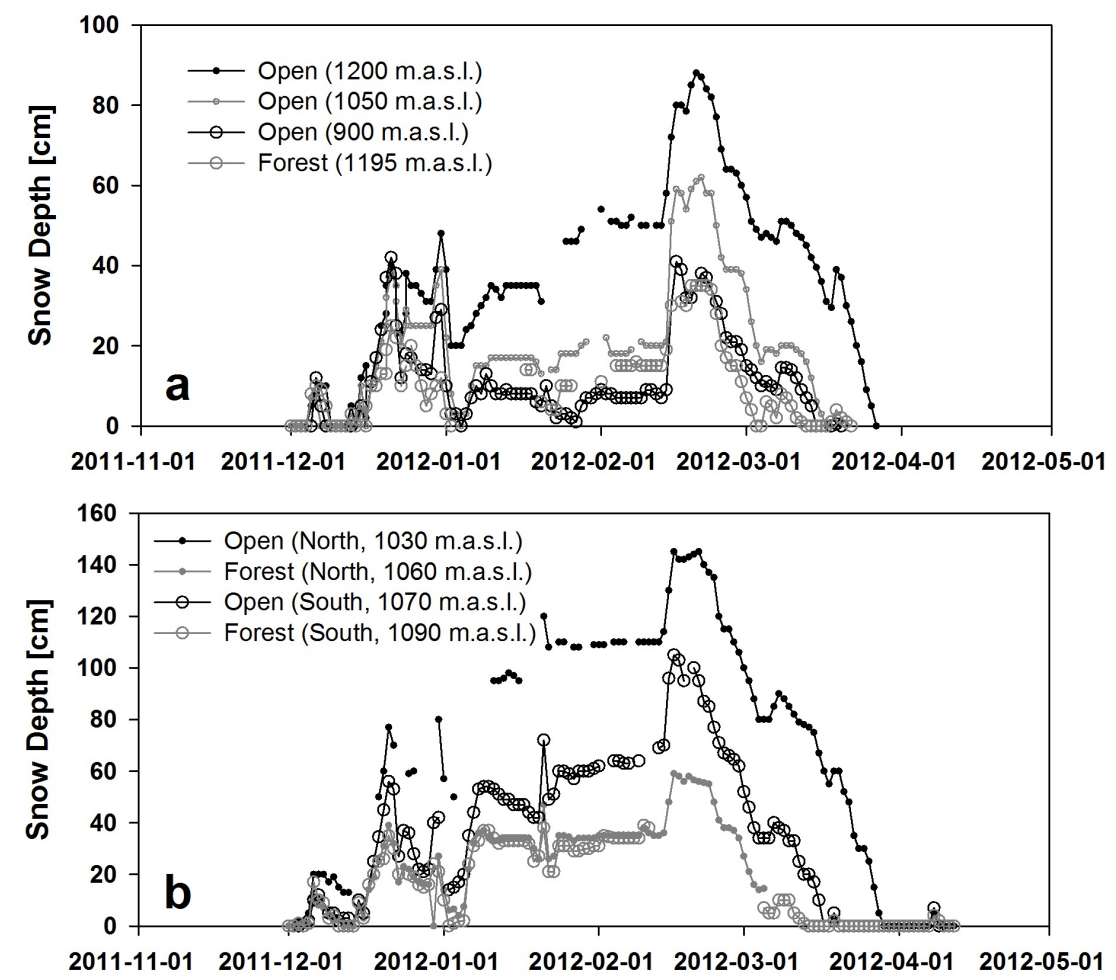

Fig. 6. Snow depths dynamics at 8 locations in the Brugga catchment (a) and the Breg catchment (b) in the winter season 2011/2012 derived from the digital images.

covered canopy, respectively. It is important to note that the fraction of white pixels within the defined ROI depends on the camera position, view angle and distance of the camera to the canopy. Therefore, this method at least initially only provides relative values for the total snow load within the forest canopy. For pictures taken from outside the forest, three polygon masks (ROIs) were defined in the canopy. The ROIs were chosen to cover a large section of the canopy (low branches as well as high branches) to get a representative overall estimate of the fraction of snow within the canopy.

A threshold has to be defined in order to distinguish white from and non-white pixels. This threshold was derived from analysing the RGB colour space for snow versus no-snow pixels. We used a threshold of 50 (above $50=$ snow, below $50=$ non-snow), which seemed to be the most appropriate threshold for differing illumination conditions. The sensitivity of the analysis on the chosen threshold was tested by recalculating the three polygon masks with thresholds of $50 \pm 10$ at one location with 129 images from 1 December 2011 through 2 April 2012. A threshold of 40 had on average $+1.2 \%$ white pixels (compared to a threshold of 50) within the three polygon masks, whereas a reduction of the snow covered pixels of $0.6 \%$ was observed for a threshold of 60. The differences in the fraction of white pixels of the three polygon masks placed at different positions within the canopy for the same period at that location was also estimated. There was a difference of $1 \%$ (standard deviation of
$2 \%$ ) between polygon mask 1 and 2 and a difference of $1.1 \%$ (standard deviation of $4.1 \%$ ) between polygon mask 1 and 3 , respectively.

The images could also be used to identify the state of precipitation at the camera locations. For this we do not used image analysis. The images were analysed visually for different events. Since the digital time-lapse cameras were deployed at different altitudes, the images could then be used to determine elevation ranges for the snow line during different winter precipitation events.

\section{Results}

\subsection{Snow depth}

Figure 6a shows the snow depth at three open and one forest locations of similar exposition, but different elevation. As expected the snow depths increase with increasing elevation at the open locations. It is interesting to note that the snow depths at the peak of the snowpack differ by as much as $53 \mathrm{~cm}$ (150 $\mathrm{mm}$ SWE) between the highest and lowest location. Furthermore, the analysis shows that the snow cover duration was about 16 days shorter for the 2011/2012 winter for the $900 \mathrm{~m}$ a.s.l. location compared to the $1200 \mathrm{~m}$ a.s.l. location. A comparison with the fourth location, which was situated underneath a dense forest canopy at an elevation of 

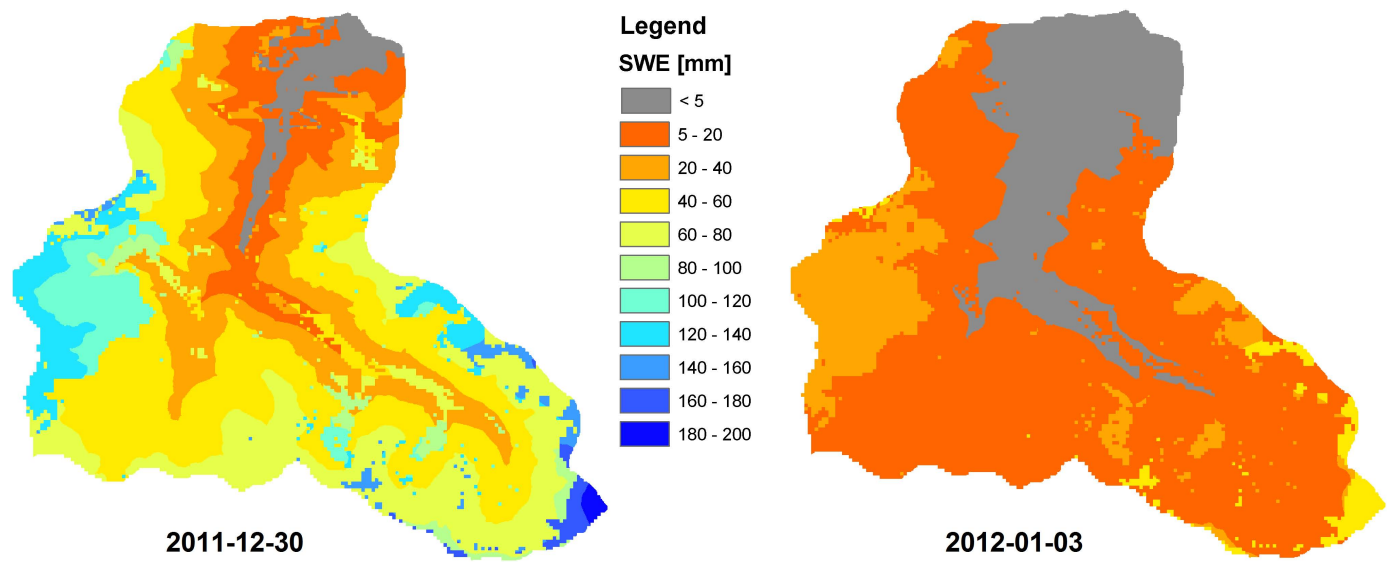

Fig. 7. SWE distribution in the Brugga catchment based on the snow depths derived from 19 camera locations and a simple linear regression model for forested and open areas before and after a rain-on-snow flood event on 2 January 2012.

$1195 \mathrm{~m}$ a.s.l. highlights the strong effect a forest canopy has on the snow cover distribution in watersheds. A difference of $55 \mathrm{~cm}$ (155 mm SWE) was observed for peak snow depth (around 22 February 2012), while in the spring the ground underneath the forest first became snow free 27 days before the snow on the adjacent open meadow disappeared.

Figure $6 \mathrm{~b}$ presents the snow depths during the winter 2011/2012 at four different locations at similar elevation, but different expositions and land cover. The influence of the exposition can be clearly seen for the two open locations with a significantly deeper snowpack on the north-facing slope. The overall maximum difference in snow depth between the two open locations is about $30 \mathrm{~cm}$ (or about $90 \mathrm{~mm} \mathrm{SWE}$ ). The observed snow depths at the two forest locations are nearly identical suggesting that exposition does not play an important role for snow accumulation under forest canopies at that location. The results, however, once again shows the great importance the forest cover has on the snow cover as there are large differences in snow depth between open and forest locations. Figure 6 also shows the great potential of the camera pairs (open vs. forest locations) used in the current study to investigate the influence of a vegetation cover on the snowpack beneath in considerable detail. Overall, the presented results demonstrate the crucial importance of determining the small scale snow cover variability even in medium elevation mountain range for a wide variety of hydrologic and ecologic aspects.

Based on the snow depth observations at the 19 camera locations throughout the Brugga watershed and snow density measurements from manual snow surveys, the spatial distribution of the SWE in the Brugga catchment prior to and after a rain on snow (ROS) event on 2 January 2012 was determined using a linear regression model (Fig. 7). The intention of this analysis is to show the potential of a camera network to deliver useful spatially distributed data of snow depth or SWE, rather than presenting a sophisticated approach to interpolate the point data spatially. The predictor of linear regression model is only elevation and two models for the two land-use types open and forest were applied without considering further predictors like different forest types, aspect or other topographic influences. For the snow surveys we used standard snow tubes to determine snow depth and snow density. The surveys were carried out at several elevations and separately for forested and open sites. Such a snow survey was carried out just prior to and shortly after the observed ROS event and the results were used to convert snow depth to SWE prior to the interpolation of the data.

SWE was calculated for each $10 \mathrm{~m} \times 10 \mathrm{~m}$ grid square in the catchment using elevation and land cover data. The flood peak observed on 2 January 2012 (see Fig. 8) was categorised as a $2 \mathrm{yr}$ flood event at the basin outlet. More extreme flood discharges were measured in some of the tributaries. The flood was generated by both liquid precipitation and snowmelt water. There was a snow cover present throughout the catchment prior to the event ranging from a few $\mathrm{cm}$ in the lowest parts to more than $50 \mathrm{~cm}$ in the highest parts of the catchment. Snow depths and consequently SWE decreased significantly at all altitudes during this ROS event. With the linear regression model a basin wide mean SWE of $56 \mathrm{~mm}$ was calculated for the snow cover prior to the event, whereas a mean SWE of $13 \mathrm{~mm}$ was determined for the snow cover after the event. Therefore, a total of $43 \mathrm{~mm}$ of SWE melted during the event. Total precipitation was $44 \mathrm{~mm}$ during this event. Assuming a negligible change in storage within the catchment these input values $(43 \mathrm{~mm}+44 \mathrm{~mm}=87 \mathrm{~mm})$ match the observed total runoff of $83 \mathrm{~mm}$ very well. The numbers also show the importance of the snowmelt for this flood event as about half of the available flood peak input resulted from the rain-on-snow melt of the pre-existing snow cover. Measured snow depths from 9 LOCUS station pairs (forest/open) along with snow densities from manual snow surveys were used to compare the data 


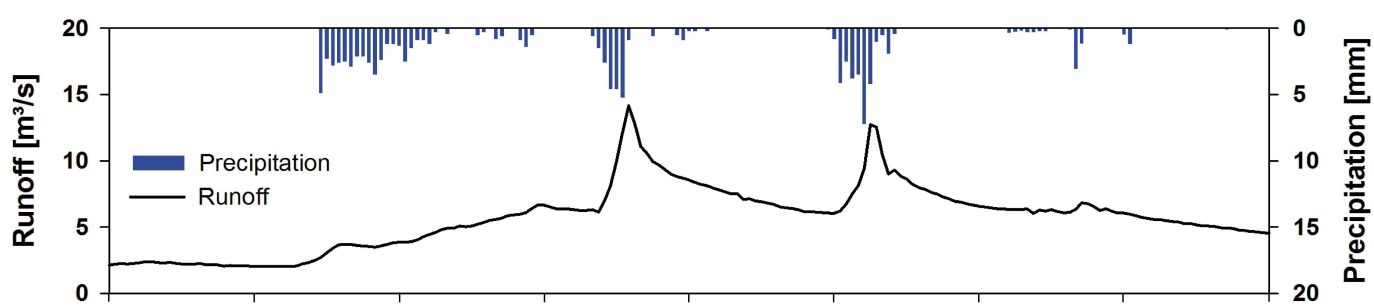

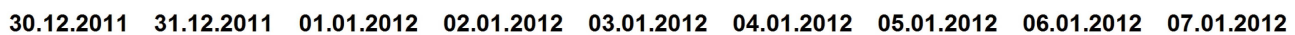
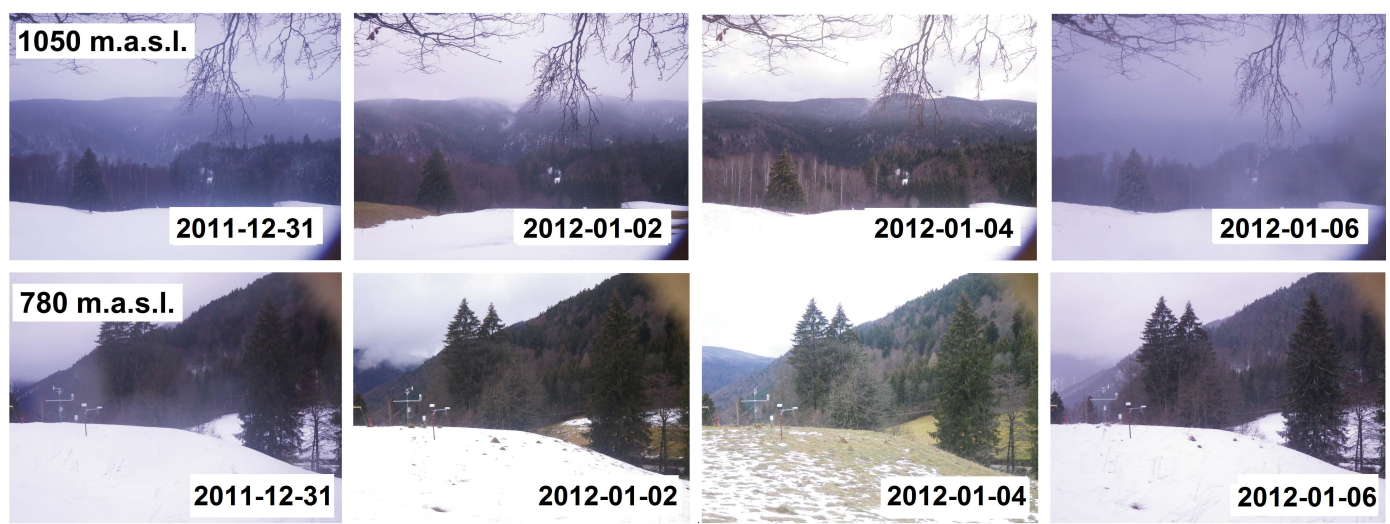

Fig. 8. Hydrograph, precipitation and time lapse photographs for the Brugga basin for three runoff events at the beginning of January 2012 .

from the linear regression model with observed SWE values. The result of this comparison can be found in Table 1.

Subsequently, the time-lapse images from different locations throughout the catchment were used for a further, detailed, interpretation of the hydrograph for this and a subsequent runoff event 2 days later (Fig. 8). Despite higher precipitation intensity and amount the later flood peak was slightly lower. The pictures show that most snow in the catchment had disappeared during the ROS event on 2 January 2012. Therefore, the water available for runoff during this event was virtually limited to rainwater and, as a result, discharge did not rise as high. Another precipitation event (6 January 2012) caused nearly no runoff increase, because, as the pictures indicate, precipitation fell as snow in most parts of the catchment. This analysis further illustrates the usefulness of time-lapse photography for hydrologic purposes.

\subsection{Snow canopy interception}

The experimental setup presented in this study allows a continuous observation of the forest canopy and the temporal evolution of the snow interception in the canopy at different topographic situations and during various climatic conditions. Figure 9 shows the snow interception results obtained from images taken by a camera installed at $900 \mathrm{~m}$ a.s.l. altitude and a viewing direction of north-east. Daily interception values from the beginning of December 2011 through end of February 2012 are shown. Several snowfall events could be observed during this period. Events of particular interest are
Table 1. Comparison of mean SWE values derived from the cameras and a simple linear regression model with SWE values observed with a snow monitoring station network.

\begin{tabular}{llccc}
\hline Date & $\begin{array}{c}\text { Land- } \\
\text { cover }\end{array}$ & $\begin{array}{c}\text { Mean } \\
\text { observed } \\
\text { SWE } \\
{[\mathrm{mm}]}\end{array}$ & $\begin{array}{c}\text { Mean } \\
\text { simulated } \\
\text { SWE } \\
{[\mathrm{mm}]}\end{array}$ & $\begin{array}{c}R^{2} \text { observed } \\
\text { vs. modelled }\end{array}$ \\
\hline 30 Dec 2011 & Open & 73.1 & 76.5 & 0.92 \\
& Forest & 55.1 & 58.2 & 0.75 \\
\hline 3 Jan 2012 & Open & 30.4 & 18.5 & 0.53 \\
& Forest & 26.0 & 15.0 & 0.13 \\
\hline
\end{tabular}

labeled with red arrows and the corresponding pictures after the snowfall events are shown. It is interesting to note, that more snow was intercepted in the canopy on $20 \mathrm{De}-$ cember 2011 compared to 15 February 2012 even though more snow fell on 15 February. The reason is most likely the difference in air temperatures during the events. Average daily temperature on 19 and 20 December 2011 were much higher at $-1.5^{\circ} \mathrm{C}$ compared to $-5.5^{\circ} \mathrm{C}$ in February 2012 . Windspeed during the events has been measured with a Thies cup type anemometer at a nearby weather station. Average wind speed on 19 December 2011 was $0.86 \mathrm{~m} \mathrm{~s}^{-1}$ (standard deviation of $0.64 \mathrm{~m} \mathrm{~s}^{-1}$ ). Average windspeed on 20 December 2011 was $1.44 \mathrm{~m} \mathrm{~s}^{-1}$ (standard deviation of $0.75 \mathrm{~m} \mathrm{~s}^{-1}$ ), whereas it was $0.88 \mathrm{~m} \mathrm{~s}^{-1}$ (standard deviation of $0.60 \mathrm{~m} \mathrm{~s}^{-1}$ ) on 15 February 2012. Previous studies have suggested that interception efficiency increases with decreasing density of 


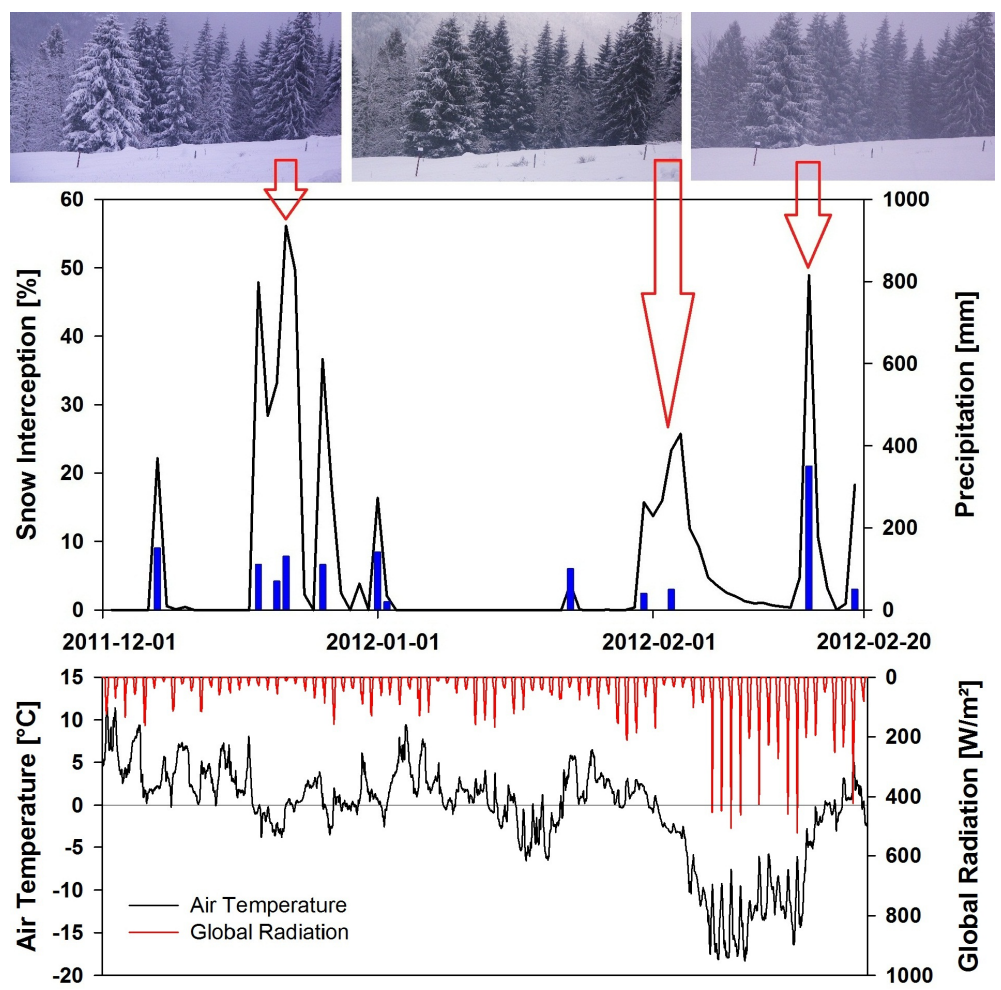

Fig. 9. Interception of snow as percentage of white pixels in the ROI in a conifer forest canopy observed during different snowfall events in winter 2011/2012 with measured air temperature and incoming solar radiation.

the falling snow, increasing temperature and decreasing wind speed (Pomeroy and Gray, 1995; Marsh, 1999). The warmer temperatures result in more flexible tree limps and lead to the building of ice bridges between the individual needles and snow crystals, therefore, allowing more snow to be intercepted. The results of this study clearly support this assumption.

The event around 3 February 2012 is special in terms of the snow removal from the canopy. The sublimation or unloading of snow from the canopy was much slower compared to the other events observed. This behaviour can most likely be attributed to the meteorological conditions at a nearby weather station observed at the time of the event. Air temperatures were consistently below freezing and incoming solar radiation was high during the entire period after the 3 February 2012 event. For the other events shown in Fig. 9, observed air temperature was higher and the radiation energy input was lower. This analysis indicates that sublimation of intercepted snow directly back to the atmosphere dominated this event. This is a much slower process than the mass unload and melt water drip processes, that were most likely responsible for the quick disappearance of the intercepted snow after the other events.

Figure 10 shows the comparison of the snow interception of similar forests on a north-facing versus a south-facing slope for a snowfall event in February 2012 in the Breg catchment. The snowfall event was followed by an overcast day with freezing temperatures where the snow remained in the canopy at both expositions. The following sunny day with moderate temperatures close to $0^{\circ} \mathrm{C}$ caused an abrupt decrease in intercepted snow. The comparison shows that the release of the snow interception storage progressed much faster at the south-facing canopy. As a result the forest canopy on the south-facing slope was snow free two days earlier compared to the canopy on the north-facing slope probably due to a more intense input of solar radiation to the south facing slope.

These results indicate the difficulties in modelling the unloading of snow with simple interception models (e.g., Hedstrom and Pomeroy, 1998) in this environment as compared to colder environments where these kinds of studies have so far often been conducted. It also further highlights the importance of having continuous observations in various topographical situations to better understand the relative importance of the involved processes in relation to topography and meteorological conditions.

\subsection{Albedo}

The albedo of a snow cover provides important information about the status of the snow and its temporal evolution is a crucial factor for the calculation and modelling of the energy balance of the snow. Visible albedo was calculated from 

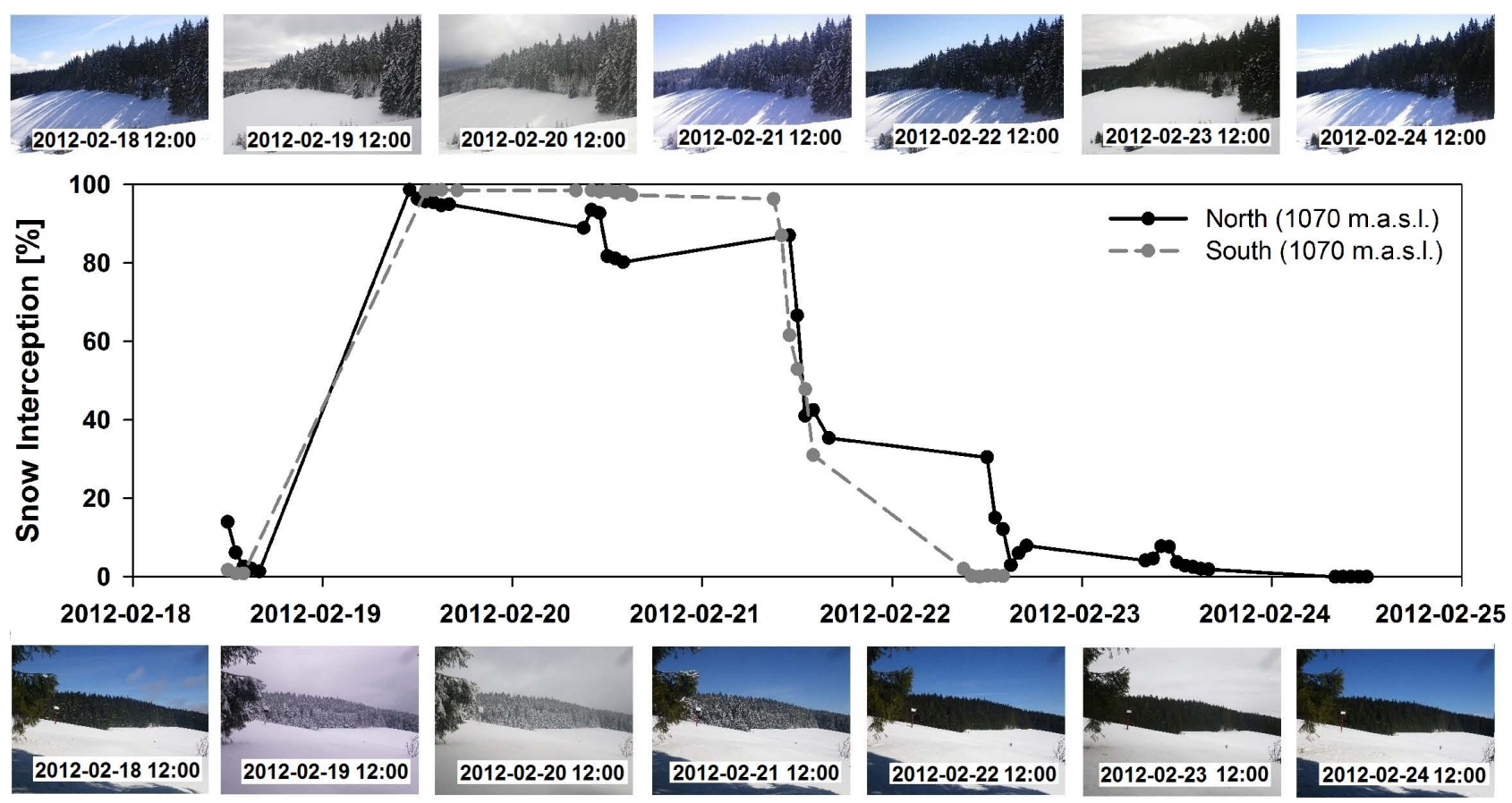

Fig. 10. Snow interception as percentage of white pixels in the ROI in the conifer forest canopy of a north facing and a south facing slope, respectively.

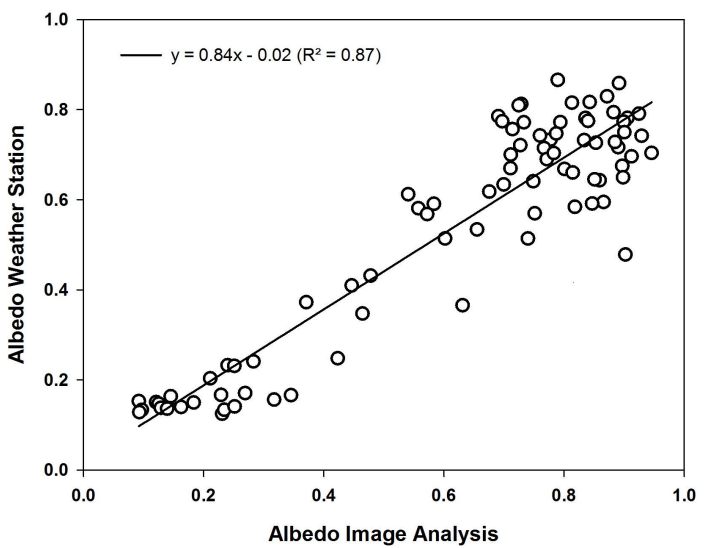

Fig. 11. Daily average albedo values measured at the weather station versus daily average albedo values derived from the image analysis.

the digital images. In the visible range, measured albedo values of fresh snow are generally high. Figure 11 shows the daily averages of albedo derived from hourly images plotted against the daily averages measured at a weather station at the same location for the whole winter season 2011/2012. The albedo was measured with a standard star Albedometer (Nova Lynx 8104). The uncalibrated daily mean albedo values explain $87 \%$ of the variance of the measured values and the calculated slope of 0.84 indicates a slight overestimation of the range of measured albedo values.
Figure 12 shows the temporal evolution of the albedo obtained from the time-lapse images compared to the albedo measured by a weather station from 1 December 2011 through 12 March 2012. Bars indicating fresh snowfall were plotted when the new snow depth was $\geq 5 \mathrm{~cm}$. The increase of the albedo caused by new snow and a subsequent decrease can be clearly seen in the graph. Albedo values of the surface during snow free periods are higher at the end of the winter. This can be explained by a bleaching of the grass cover during the winter. A root-mean-squared-error (RMSE) of 0.13 and a Nash-Sutcliffe efficiency of 0.75 reveal the good correlation of the two time series shown in Fig. 12. However, the fluctuation of the albedo from day-to-day is higher for the values derived from the image analysis method than for the measured albedo values. The comparison proves the validity of the presented method to obtain meaningful albedo values using only the visible range of the electromagnetic spectrum. Subsequently, the albedo image analysis was applied to images taken at other field sites in the study area. Figure 13 shows albedo values (daily averages) of the snow surface under a conifer forest canopy and a nearby open field site for the entire winter 2011/2012. The data again clearly shows the expected increase in albedo after snowfall events. The subsequent albedo decrease underneath the canopy is also well reproduced by the data. A stronger decrease of albedo, probably due to needles, small branches, and other debris deposited on the snow cover under the forest canopy, can be seen after some events. The earlier melt-out of the snowpack under the forest canopy is also reflected in the presented data. 


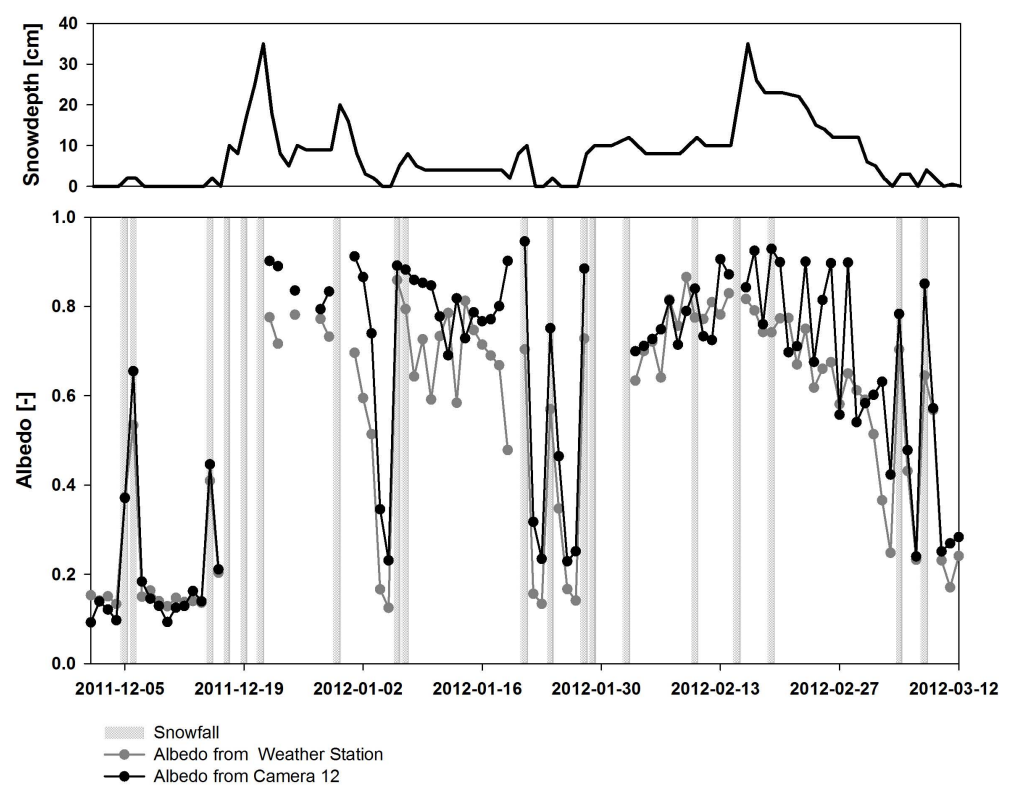

Fig. 12. Comparison of albedo values derived from the image analysis and measured albedo values at the weather station for the winter season 2011/2012 with snowfall events. Snow depth dynamic at this location is shown in the graph above. From the 103 day period, 86 days could be used for analysis.

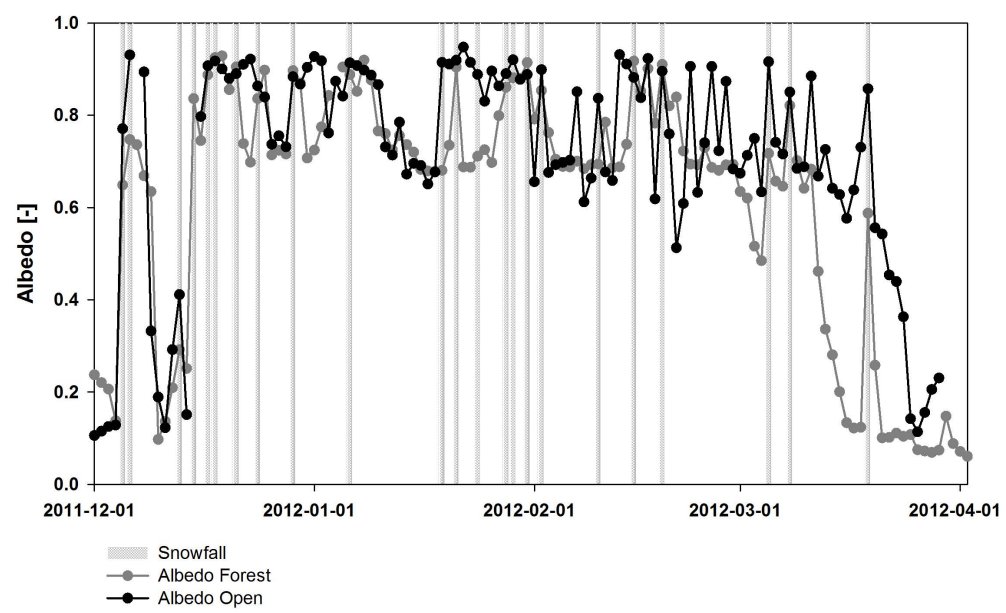

Fig. 13. Snow cover albedo under a conifer forest canopy and an open field site during the winter 2011/2012 with snowfall events.

Such continuous observations are very valuable for the improvement of snowmelt models as many of these models use open field albedo values to calculate the snow cover energy balance underneath a forest canopy. This assumption has to be tested as it could potentially lead to significant errors in the simulation of forest snowmelt rates. Unfortunately, no direct albedo measurements under the forest canopy were available to validate these results.

\subsection{State of precipitation}

Time-lapse images were also used to identify the state of precipitation during precipitation events. Due to the high number of digital cameras installed at different elevations in the study catchments, the pictures could be used to identify the elevation of the snow line and its changes over time during precipitation events. Taking the data from the LOCUS network, we were able to compare measured temperature profiles to the snow line determined from the images (Fig. 14). For the 13 December 2011 event, the snow line determined from the images was between 890 and $1010 \mathrm{~m}$ a.s.l (red box). For 27 January 2012 event, the snow line was fairly close to the $780 \mathrm{~m}$ a.s.l. since we observed a mix of rain and snow in the pictures at this altitude and snowfall was evident in the pictures of the next higher camera station $890 \mathrm{~m}$ a.s.l. (green box). For the third event shown here, 

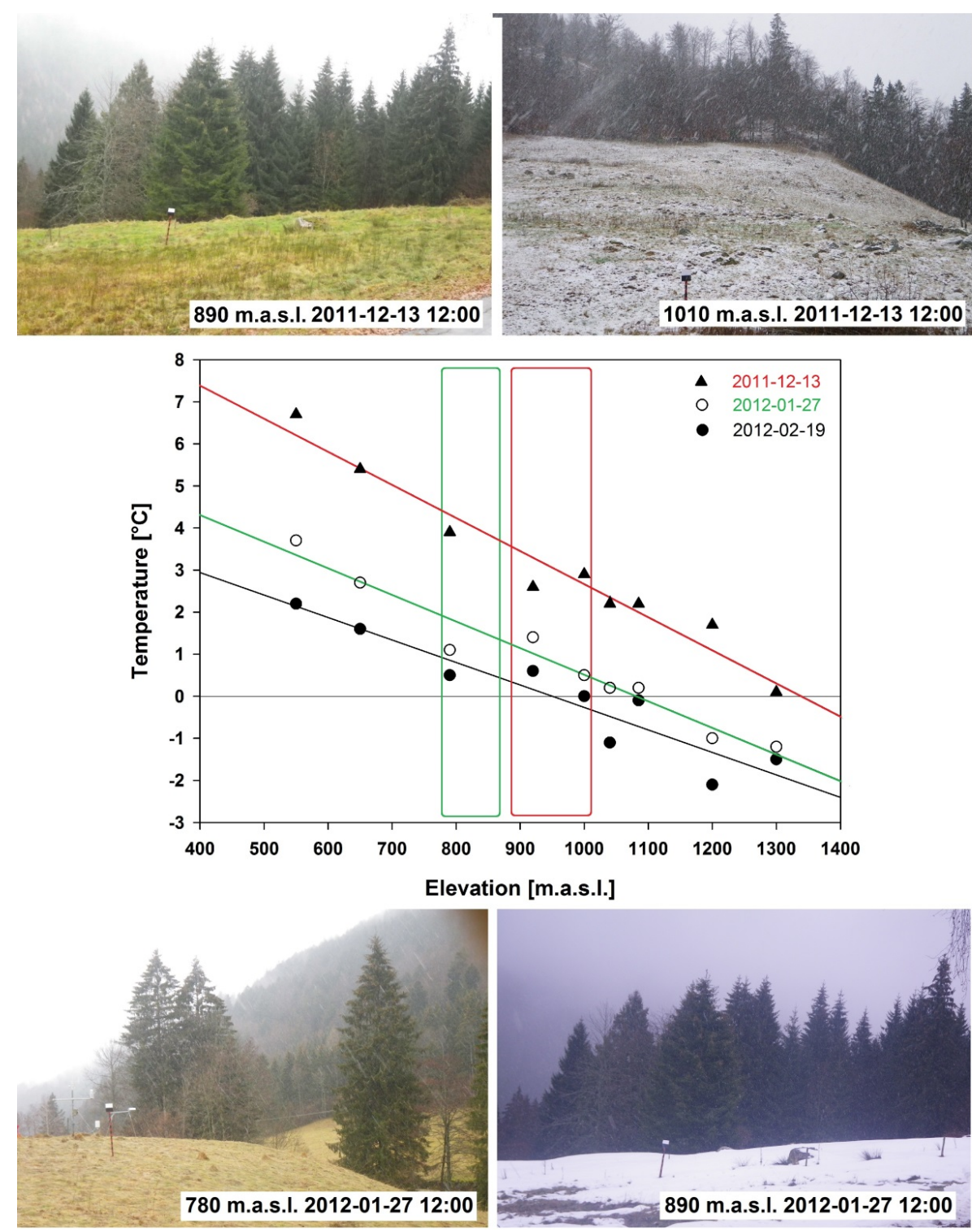

Fig. 14. Temperature profiles for different precipitation events in the Brugga catchment. Time-lapse images could be used to determine the state of precipitation.

the snow line was lower than the altitude of the lowest digital camera. Therefore, we can assume that the precipitation fell as snow in virtually the entire catchment during this event. When comparing the estimated snow lines from the digital images to the observed temperature profiles, we can see that the snow line was at an elevation with an air temperature $(2 \mathrm{~m}$ above ground) of around $3-4{ }^{\circ} \mathrm{C}$ for the 13 December 2011 event and around $2{ }^{\circ} \mathrm{C}$ for the 27 January 2012 event, respectively. Compared to many hydrological models, in particular operational models, which only use air temperature values to differentiate between rain and snow and not more sophisticated approaches like atmospheric profiles or dew point temperature calculations, these values are relatively high (e.g., Sproles et al., 2012).

\section{Discussion}

With a simple technical modification to a standard digital camera, it was possible to establish a cost and time efficient network of time-laps cameras in several mesoscale mountain catchments to perform a very detailed continuous observation of the snow cover and snow processes. However, there are some limitations concerning this technique. Gaps in the data are caused by: (1) photographs taken during night time which are useless for the analysis; (2) strong snow fall events causing frost or snow to accumulate on the lens of the camera; (3) reduced visibility due to fog; (4) images showing snow rime build up or snow sticking to the measurement scale and the black/white reference scale; (5) direct sunlight 
into the camera lens (dependent on camera location and day of the year, more a problem in early spring); (6) over exposure of the digital images and very few images mostly at forest locations that are too dark during mid-winter on overcast days. Such images had to be discarded from the image analysis. Due to the technical set-up of the camera no condensation of the camera lens was observed. On average, more images were useless for an image analysis at open field sites. At a very exposed location, $49.4 \%$ of the images potentially available for analysis (i.e., no night images) were useless for an analysis, whereas at a very sheltered location in a dense forest only $8.7 \%$ had to be discarded. On average, about $25 \%$ of the images taken at open locations and $12 \%$ from forest locations were useless for image analysis. A similar setup used to observe the snowmelt in June and July 2012 at an alpine site (Furkapass, $2375 \mathrm{~m}$ a.s.l.) in Switzerland showed with $15 \%$ an even lower percentage of unusable images (P. Schneider, personal communication, 2012).

When applying a camera network, such as the one presented in this study, several points should be considered to ensure a successful continuous observation: (1) direct insolation into the camera lens and to the reference board (overexposure) should be avoided; (2) the position of the measurement stake within the view of the camera should be as close as possible to the camera and in the middle of the field of view (this simplifies a fully automated image analysis); (3) the loss of pictures due to snow accumulation in front of the camera lens could be further limited by using a different housing design of the camera. As can be seen in Fig. 2, there is a sharp edge in the opening of the bird house in front of the camera lens where snow can accumulate; (4) the number of useless images could also be reduced by choosing not too exposed locations (considering main wind direction); (5) the camera locations should be accessible to download the images three to four times during the winter season. Unfortunately, it is not possible to switch off the camera during nighttime, which would increase the length of the observation period significantly. It is also not possible to increase the number of pictures taken by the camera in the interval mode (1000), which is the limiting factor on how long the camera can operate independently as the SD-cards could store many more pictures.

A fully automated analysis of the digital images was not possible since the cameras are moving slightly due to wind or snow on the camera housing and after the sites were visited to download the images. Further improvements of the image analysis software could account for these limitations for example with an automatic identification of the measurement scales needed for image analysis and an automatic determination and discarding of useless images.

The determination of snow depths for the camera locations was very successful. Preferential melt and deposition of snow around the measurement scale are a minor problem when using the automated approach. That was one of the reasons why we decided to use the approach described here. The collected data is extremely useful to investigate snow accumulation and ablation processes at different time scales (hourly, daily) and for different locations. Furthermore, the data could be used to interpolate the spatial distribution and temporal evolution of a snow cover throughout a mountainous catchment in forested and open areas.

Interception in the forest canopy was calculated as a fraction of white pixel within a defined polygon mask in the canopy. Therefore, the distance of the camera to the forest, the angle of the camera view field and the forest canopy structure has an influence on the calculated results resulting in different interception values at different locations after similar snowfall amounts. However, valuable qualitative information about the interception process, exposure times and the subsequent unloading/melting processes of the snow in the forest canopy for different altitudes exposures, canopy densities and meteorological conditions could be collected with the presented approach. Therefore, this approach has the potential to improve existing interception algorithms. Some studies have investigated the interception process with direct weight measurements of single trees (Hedstrom and Pomeroy, 1998; Storck et al., 2002). However, these weighting techniques are quite complex and only provide data for one particular location and tree type. Even though providing only qualitative information about interception dynamics, the approach presented in this study is a suitable observation method to continuously monitor interception in forest canopies and we believe that this approach will provide much needed continuous information about the interception processes and can be used to significantly improve the algorithms for the simulation of interception in hydrologic models. An approach to determine quantitative data would be definitively desirable and might be developed at a later stage.

Image analysis was successfully used in this study to calculate surface albedo values from the digital images. Nevertheless, it has to be mentioned that there are some simplifications compared to other approaches (Corripio, 2004) and the approach presented in this study has some limitations.

Although, the albedo is dependent on the angle of the incoming solar radiation (Wiscombe and Warren, 1980; Warren, 1982), we did not apply a correction for the different daily and seasonal illumination angles of incoming direct solar radiation on the reference card and the surface angles during clear sky conditions. As Corripio (2004) has shown, applying such a correction leads to very a good agreement between measured and estimated albedo values from terrestrial images. Applying such a correction may have improved our results, but would have also have introduced more complexity. Compared to Corripio (2004), we apply our image analysis in the near distance range of the camera where we have constantly changing surfaces as already explained in Sect. 2.3 Image Analysis. We tried to mitigate the errors introduced by these effects by only looking at calculated daily means of snow albedo from the hourly images during daylight. A correction for illumination angles would realistically 
only affect snow albedo on sunny days when a significant portion of the global radiation consists of direct radiation as diffuse radiation is not affected by the changing illumination angles. Clearly such days are observed very rarely over the winter period in our study area. Within the time period of 103 days between 1 December 2011 and 3 December 2012 only about one quarter of these days (26 days) had absolutely clear sky conditions where a correction for direct radiation would have been required. Three quarters of the study period showed conditions with mostly diffuse illumination conditions where such a correction is not required. Furthermore, an illumination correction requires the determination of the direct solar radiation component which in turn requires the calculation of a cloudiness index. Since cloudiness is spatially very variable, a determination of the direct solar component on an hourly basis for 45 camera locations would require additional measurements very close to the camera locations. While there are some empirical formulae using climate variables, most of those are rather unreliable and would probably introduce an additional error into the analysis. The only reliable way would have been to set up radiometers next to each of the cameras, which seems rather unreasonable and would undermine the proposed advantage of using a timelaps camera network.

Despite the simplifications compared to other approaches named in this discussion, we were able to extract useful data of snow surface albedo at different locations without a calibration of the results with measured albedo values. The data show realistic values of a high albedo values after a new snowfall, a subsequent decrease in albedo, and a strong decrease for a melting snow pack with an increasing snow free area.

For the daylight photographs it was possible to identify the state of precipitation and, thus, the snow line by using the information from the cameras at different altitudes. The observed temperature threshold values are relative high compared to the frequently used threshold temperatures in many hydrological models. Unfortunately, some of the major snowfall events are obviously occurring during nighttime, which is a clear limitation of this technique.

The information from time-lapse images can also be used to verify snow cover patterns or snow processes simulated from hydrological models (e.g., Farinotti et al., 2010; Parajka et al., 2012a). The spatial and temporal high resolution data collected from a camera network such as the one presented in this study provides a very useful dataset which could be used to test assumptions in existing hydrological models and to improve the simulation of the spatio-temporal variability of seasonal snow covers and the related processes at the plot and catchment scale. Instead of using labor intensive snow surveys (Parajka et al., 2012b) a network of cameras could be furthermore used to validate satellite snow datasets especially in forested mountain environments. Other applications not explicitly shown in this paper are the estimation of cloudiness, which is useful for energy balance calculations, and the calculation of snow covered area (SCA), which could be used to better estimate the relationship between snow depth and SCA crucial in many hydrologic models.

\section{Conclusions}

The study highlighted the usefulness of a distributed network of standard digital time-lapse cameras for snow observations in mesoscale mountain catchments with exemplary datasets. A simple technical modification related to the power supply of the cameras is needed to run the standard digital cameras autonomous at any location in the field. The presented experimental design is an appropriate technique to realise a continuous observation of the spatial distribution and temporal evolution of key aspects of a seasonal snow cover throughout a mesoscale catchment. The method is easy to accomplish, low-cost and provides useful data about snow depth and snow albedo as well as important snow processes such as snow interception and state of precipitation. Furthermore, the spatially distributed design of the camera network provides reliable continuous information for the identification of the snow line during winter precipitation events and the interpretation of snowmelt runoff hydrographs. The time-laps cameras could also be used for other applications where visible information could provide useful information of its own or together with additional observations.

Acknowledgements. For the valuable suggestions during the review process contributing to improve the paper we would like to thank the reviewers J. Corripio, J. Parajka, and an anonymous third reviewer. Furthermore, we would like to thank the German Research Foundation (DFG) for the funding of the project "Field Observations and Modelling of Spatial and Temporal Variability of Processes Controlling Basin Runoff during Rain on Snow Events". The article processing charge was funded by the German Research Foundation (DFG) and the Albert-Ludwigs University Freiburg in the funding programme Open Access Publishing. We would also like to thank our field assistants Franziska Zieger, Daniel Günther and Denis Blümel for their valuable help in the field and the technicians of the institute, Emil Blattmann and Lukas Neuhaus.

Edited by: H. H. G. Savenije

\section{References}

Corripio, J. G.: Snow surface albedo estimation using terrestrial photography, Int. J. Remote Sens., 25, 5705-5729, 2004.

Etchevers, P., Martin, E., Brown, R., Fierz, C., Lejeune, Y., Bazile, E., Boone, A., Dai, Y. J., Essery, R., Fernandez, A., Gusev, Y., Jordan, R., Koren, V., Kowalczyk, E., Nasonova, N. O., Pyles, R. D., Schlosser, A., Shmakin, A. B., Smirnova, T. G., Strasser, U., Verseghy, D., Yamazaki, T., and Yang, Z. L.: Validation of the energy budget of an alpine snowpack simulated by several snow models (SnowMIP project), Ann. Glaciol., 38, 150-158, 2004. 
Farinotti, D., Magnusson, J., Huss, M., and Bauder, A.: Snow accumulation distribution inferred from time-lapse photography and simple modelling, Hydrol. Process., 24, 2087-2097, 2010.

Floyd, W. and Weiler, M.: Measuring snow accumulation and ablation dynamics during rain-onsnow events: innovative measurement techniques, Hydrol. Process., 22, 4805-4812, 2008.

Garen, D. C. and Marks, D.: Spatially distributed energy balance snowmelt modelling in a mountainous river basin: estimation of meteorological inputs and verification of model results, J. Hydrol., 315, 126-153, 2005.

Gorski, K. M.: Albedo project, https://sites.google.com/site/ albedoproject/home, last access: 4 February 2013.

Gray, D. M. and Landine, P. G.: Albedo model for shallow prairie snowcovers, Can. J. Earth Sci., 24, 1760-1768, 1987.

Greuell, W., Reijmer, C. H., and Oerlemans, J.: Narrowband-tobroadband albedo conversion for glacier ice and snow based on aircraft and near-surface measurements, Remote Sens. Environ., 82, 48-63, 2002.

Hardy, J., Melloh, R., Robinson, P., and Jordan, R.: Incorporating effects of forest litter in a snow process model, Hydrol. Process., 14, 3227-3237, 2000.

Hedstrom, N. R. and Pomeroy, J. W.: Measurements and modelling of snow interception in the boreal forest, Hydrol. Process., 12, 1611-1625, 1998.

Hinkler, J., Pedersen, S. B., Rasch, M., and Hansen, B. U.: Automatic snow cover monitoring at high temporal and spatial resolution, using images taken by a standard digital camera, Int. J. Remote Sens., 23, 4669-4682, 2002.

Jonas, T., Marty, C., and Magnusson, J.: Estimating the snow water equivalent from snow depth measurements in the Swiss Alps, J. Hydrol., 378, 161-167, 2009.

Jost, G., Weiler, M., Gluns, D. R., and Alila, Y.: The influence of forest and topography on snow accumulation and melt at the watershed-scale, J. Hydrol., 347, 101-115, 2007.

Jost, G., Moore, R. D., Weiler, M., Gluns, D. R., and Alila, Y.: Use of distributed snow measurements to test and improve a snowmelt model for predicting the effect of forest clear-cutting, J. Hydrol., 376, 94-106, 2009.

Klein, A. G. and Stroeve, J.: Development and validation of a snow albedo algorithm for the MODIS instrument, Ann. Glaciol., 34, 45-52, 2002.

Knap, W. H., Brock, B. W., Oerlemans, J., and Willis, I. C.: Comparison of Landsat TM-derived and ground-based albedos of Haut Glacier d'Arolla, Switzerland, Int. J. Remote Sens., 20, 32933310, 1999.

Link, T. and Marks, D.: Point simulation of seasonal snowcover dynamics beneath Boreal forest canopies, J. Geophys. Res., 104, 841-857, 1999.

Lundberg, A. and Koivusalo, H.: Estimating winter evaporation in boreal forests with operational snow course data, Hydrol. Process., 17, 1479-1493, 2003.

Marsh, P.: Snowcover formation and melt: Recent advances and future prospects, Hydrol. Process., 13, 2117-2134, 1999.
Mazurkiewicz, A. B., Callery, D. G., and McDonnell, J. J.: Assessing the controls of the snow energy balanceand water available for runoff in a rain-on-snowenvironment, J. Hydrol., 354, 1-14, 2008.

Melloh, R. H., Hardy, J. P., Davis, R. E., and Robinson, P. B.: Spectral albedo/reflectance of littered forest snow during the melt season, Hydrol. Process., 15, 3409-3422, 2001.

Parajka, J., Haas, P., Kirnbauer, R., Jansa, J., and Blöschl, G.: Potential of time-lapse photography of snow for hydrological purposes at the small catchment scale, Hydrol. Process., 26, 3327-3337, 2012a.

Parajka, J., Holko, L., Kostka, Z., and Blöschl, G.: MODIS snow cover mapping accuracy in a small mountain catchment - comparison between open and forest sites, Hydrol. Earth Syst. Sci., 16, 2365-2377, doi:10.5194/hess-16-2365-2012, 2012b.

Pomeroy, J. W. and Gray, D. M.: Snowcover accumulation in cold climate forests, Hydrol. Process., 16, 3543-3558, 1995.

Pomeroy, J. W., Shook, K. R., Toth, B., Essery, R. L. H., Pietroniro, A., and Hedstrom, N.: An evaluation of snow accumulation and ablation for land surface modelling, Hydrol. Process., 12, 2339 2367, 1998.

Pomeroy, J. W., Gray, D. M., Brown, T., Hedstrom, N. R., Quinton, W. L., Granger, R. J., and Carey, S. K.: The cold regions hydrological model: a platform for basing process representation and model structure on physical evidence, Hydrol. Process., 21, 2650-2667, 2007.

Storck, P., Lettenmaier, P. D., and Bolton, S. M.: Measurement of snow interception and canopy effects on snow accumulation and melt in a mountainous maritime climate, Oregon, United States, Water Resour. Res., 38, 1-16, 2002.

Stottlemyer, R. and Troendle, C. A.: Effect of canopy removal on snowpack quantity and quality, Fraser Experimental forest, Colorado, J. Hydrol., 245, 165-176, 2001.

Sproles, E., Nolin, A., Rittger, K., and Painter, T.: Climate change impacts on maritime mountain snowpack in the Oregon Cascades, Hydrol. Earth Syst. Sci. Discuss., 9, 13037-13081, doi:10.5194/hessd-9-13037-2012, 2012.

Varhola, A., Wawerla, J., Weiler, M., Coops, N. C., Bewley, D., and Alila, Y.: A New Low-Cost, Stand-Alone Sensor System for Snow Monitoring, J. Atmos. Ocean. Tech., 27, 1973-1978, 2010.

Warren, S. G.: Optical properties of snow, Rev. Geophys., 20, 6789, 1982.

Warren, S. G. and Wiscombe, W. J.: A model for the spectral albedo of snow, II: Snow containing atmospheric aerosols, J. Atmos. Sci., 37, 2734-2745, 1980.

Winkler, R. D., Splitthouse, D. L., and Golding, D. L.: Measured differences in snow accumulation and melt among clearcut, juvenile and mature forests of southern British Columbia, Hydrol. Process., 19, 51-62, 2005.

Wiscombe, W. J. and Warren, S. G.: A model for the spectral albedo of snow, I: pure snow, J. Atmos. Sci., 37, 2712-2733, 1980. 